\title{
Real-time measurements of formaldehyde emissions in a gross anatomy laboratory
}

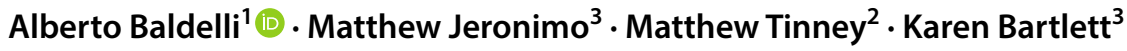

Received: 18 December 2019 / Accepted: 18 March 2020 / Published online: 28 March 2020

(c) Springer Nature Switzerland AG 2020

\begin{abstract}
Formaldehyde is recognized to be a carcinogen and a genotoxic indoor pollutant. The National Institute for Occupational Safety and Health (NIOSH) identify 1 ppm as the ceiling limit, a value which should not be exceeded at any time. This low ceiling limit generates the need for real-time monitoring; which can, however, lack in accuracy. In this project, formaldehyde low-cost monitors are both evaluated in a laboratory platform and in an indoor environment. Using a controlled environmental chamber, the formaldehyde sensors show a linear regression coefficient $R^{2}$ of 0.98 when compared to the reference method [NIOSH 2016, based on 2,4-dinitrophenylhydrazine (DNPH) derivatization]. Readings taken with the calibrated low-cost monitors in a gross anatomy laboratory, where embalmers, medical students and staff are exposed to formaldehyde and other toxic volatile organic compounds, show that the embalming and dissection processes generate average values of about 900 and $1300 \mathrm{ppb}$, respectively, when corrected for phenol interference. The corrected average values are within $20 \%$ of the reference method values. Real-time data for the same processes show maximum concentrations (1-min average) of about $3.5 \mathrm{ppm}$ in both embalming procedure and dissection laboratory. Therefore, real-time monitoring can show values of formaldehyde exceeding the acceptable exposure short-term limit and ceiling limit.
\end{abstract}

Keywords Formaldehyde detection · Embalming procedure $\cdot$ Gross anatomy laboratory $\cdot$ Morgue air quality $\cdot$ Real-time monitoring $\cdot$ Federal reference method

\section{Introduction}

Formaldehyde is widely recognized as a dangerous indoor pollutant $[6,50]$. The International Agency for Research on Cancer (IARC) recognizes formaldehyde as a carcinogen [24]; it can cause nasopharyngeal cancer in humans. Current research also indicates that formaldehyde is genotoxic. About $0.36 \mathrm{ppm}$ is enough to provoke irritation to the eyes [7]. Therefore, for an exposure time of $15 \mathrm{~min}$, $0.1 \mathrm{ppm}(100 \mathrm{ppb})$ is recommended to prevent sensory irritation in the general population [9]. Controlled studies in humans report that for less than an hour of exposure to formaldehyde concentrations below $2 \mathrm{ppm}$, no toxicological effects on the eyes or on tissues in the upper respiratory tract are produced [19]. However, long-term exposures to more than $2.5 \mathrm{ppm}$ show a high possibility of developing myeloid leukemia $[8,9,19]$. Hence, the Occupational Safety and Health Administration (OSHA) permissible exposure limits (PEL) are set at an 8-h time of $0.75 \mathrm{ppm}$ and a 15-min short-term exposure limit (STEL)

Electronic supplementary material The online version of this article (https://doi.org/10.1007/s42452-020-2569-7) contains supplementary material, which is available to authorized users.

$\triangle$ Alberto Baldelli, baldelli.alberto@yahoo.com | 'Department of Mechanical Engineering, University of British Columbia, 6250 Applied Science Ln \#2054, Vancouver, BC V6T 1Z4, Canada. ${ }^{2}$ Department of Cellular and Physiological Sciences, University of British Columbia, 2350 Health Sciences Mall, Vancouver, BC V6T 1Z3, Canada. ${ }^{3}$ School of Population and Public Health, University of British Columbia, 2206 E Mall, Vancouver, BC V6T 1Z3, Canada. 
of $2 \mathrm{ppm}$. The National Institute for Occupational Safety and Health (NIOSH) recognizes an 8-h time-weighted average (TWA) of $0.016 \mathrm{ppm}$ and a STEL of $0.1 \mathrm{ppm}$ [19], while the most recently set threshold limit values (TLV) from the American Conference of Governmental Industrial Hygienists (ACGIH) list a TWA of $0.1 \mathrm{ppm}$ and a $15-\mathrm{min}$ STEL of $0.3 \mathrm{ppm}$.

Formaldehyde can be generated by a broad range of sources, such as biomass combustion, oxidation of volatile organic compounds (VOCs) and reactions between ozone (mainly from outdoors) and alkenes [4, 28, 37, 45, 55]. Some indoor sources are smoking, heating, cooking, candle or incense burning, building materials and consumer products $[23,25,36,38,43]$. In a common North American household, daily 8-h TWA levels of formaldehyde vary between 16 to a maximum of $77 \mathrm{ppb}$ [23]. Much higher levels are found in a gross anatomy laboratory [29, 48]; 8-h average and maximum formaldehyde levels are about 0.7 and 3 ppm, respectively [42]. Another toxic gas present in a gross anatomy laboratory is phenol [22,46], which is not only present in the embalming fluid but it is released in the early stages of human body decomposition [53]. Both NIOSH and OSHA established $5 \mathrm{ppm}$ as an 8-h TLV. NIOSH recommends $15.6 \mathrm{ppm}$ as the ceiling level, the maximum value that a person should avoid, for phenol exposures [39]. This limit decreases when considering women because of reproductive hazards [56].

In a gross anatomy laboratory, the maximum formaldehyde air concentrations are found during the embalming procedure in the morgue [42]. Several embalming procedures are used; however, differences are minor. The first step in the embalming procedure involves the drilling of a hole in the brain. Later, the blood is removed from the body veins and it is substituted with a formaldehydebased chemical. The total time required to infuse $15 \mathrm{~L}$ of the embalming fluid is about $40 \mathrm{~min}$. In addition, the organs in the chest cavity and the abdomen are perforated and drained of residual fluids; formaldehyde-based chemicals are then injected [30]. Common embalming mixtures range from 7 to $37 \%$ formaldehyde by weight [20]. Some alternatives to the traditional embalming fluids are under development; however, formaldehyde-based embalming fluids are still the majority used $[20,26]$. Furthermore, to reduce the emissions of formaldehyde and phenol the cadaver is perfused with a $20 \%$ Infutrace solution [60] after a 7-day fixation period. Infutrace, a proprietary, non-toxic solution with undisclosed chemical compounds, reacts gently with the specimen fixed with a formaldehydebased embalming fluid and produces a significant reduction, about $95 \%$, of the sum of formaldehyde and phenol vapors [30].

On average, an embalmer spends about 2 days a week working on embalming bodies; thus, there is the potential for repeated exposure to high concentrations of formaldehyde. Medical students and staff are exposed for at least $43 \mathrm{~h}$ per semester to embalmed bodies [41]. Monitoring vapor concentrations may be used to help limit the exposure of both embalmers and students to formaldehyde. The common techniques to measure formaldehyde and phenol concentrations are NIOSH 2016 and NIOSH 2546, respectively. The NIOSH 2016 method uses dinitrophenyl hydrazine (DNPH)-treated silica gel tubes, which is very consistent with little-to-no background levels of formaldehyde present. The NIOSH 2546 targets all isomers of cresol and phenol, and the sampling device used is a XAD-7 tube. Both methods have a detection limit of around $1 \mu \mathrm{g} / \mathrm{m}^{3}$ [59]. The main drawback of the NIOSH methods is their high costs. Moreover, this type of method cannot provide any real-time information on the pollutants' levels. Monitoring formaldehyde levels in real time allows for a correlation of concentration spikes to their cause. Understanding these correlations can help to reduce the shortterm exposures to both embalmers and students and to prevent their health impacts. An inexpensive, affordable, and easy-to-use method for real-time detection is low-cost monitors [1].

In recent years, many research studies have focused on the development of an accurate low-cost monitor for volatile organic compounds, specifically targeted to formaldehyde $[5,11,21,61]$. A few methods to achieve the realtime detection of formaldehyde are available, as shown in some examples reported in Table 1 [12]. In Table 1, the main research studies on the development of different methods for the detection of formaldehyde are reported. The most common methods to detect formaldehyde are colorimetric, piezoresistive, electrical impedance spectroscopy (El), and metal-oxide conductimetry (MOX) [14, 52]. The first group involves a chip made of a substrate and a coating of a material that can react with formaldehyde. The fluorescence generated by the reaction between the formaldehyde and the coating is conveyed to a photodetector. Different products vary in the substrate and the coating used (Table 1). Colorimetric sensors can show a high accuracy and the highest selectivity for a targeted gas; however, a long procedure for the sensor development is required increasing, thus, the costs [52]. Piezoelectric formaldehyde sensors use materials that generate a response once exposed to the targeted gas. The low limit of detection (LOD) and the lower influence to humidity compared to colorimetric sensor motivate recent research projects. However, high complexity in their fabrication and validation are factors that reduce their popularity [52].

Therefore, the current commercially available low-cost formaldehyde sensors are El and MOX. High availability, low costs, low limit of detection, and high selectivity are the reasons of their popularity [54]. They can be tuned to 
Table 1 Examples of research studies on the development of low-cost sensors aimed for measurements of gaseous formaldehyde

\begin{tabular}{|c|c|c|c|c|}
\hline Substrate and sensitive materials & Range [ppb] & Accuracy [ppb] & Interference & References \\
\hline \multicolumn{5}{|l|}{ Colorimetric or spectrometric } \\
\hline $\begin{array}{l}\text { Sol-gel doped with Fluoral-P mol- } \\
\text { ecules form dihydrolutidine }\end{array}$ & $30-200$ & 1 & After $12 \mathrm{~h}$ at $\mathrm{RH}^{\mathrm{b}}=70 \%$, no response & Descamps et al. [17] \\
\hline $\begin{array}{l}\text { Silica paper coated with hydroxy- } \\
\text { lamine sulfate and thymol blue }\end{array}$ & $30-1000$ & $50^{\mathrm{a}}$ & $\begin{array}{l}\text { At } \mathrm{RH}=30 \% \text {, response decreases } \\
\text { from } 300 \text { to } 200 \mathrm{ppb}\end{array}$ & Qin et al. [47] \\
\hline \multicolumn{5}{|l|}{ Piezo-resistive } \\
\hline $\begin{array}{l}\text { Piezoelectric stack composed of a } \\
\text { Mo/Ti bottom electrode coated } \\
\text { with multiwalled carbon nano- } \\
\text { tubes-polyethyleneimine }\end{array}$ & $30-1000$ & NA & $\begin{array}{l}\text { Att } \mathrm{RH}-70 \% \text {, the linearity increases } \\
\text { by } 23 \%\end{array}$ & Wang et al. [57] \\
\hline $\begin{array}{l}\text { ZnO piezoelectric film resonators } \\
\text { modified with a pure MWNTs }\end{array}$ & $20-1000$ & $5^{\mathrm{a}}$ & $\begin{array}{l}\text { At } \mathrm{RH} \text { of } 80 \%, \mathrm{LOD}^{\mathrm{b}} \text { increases from } \\
24 \text { to } 38 \mathrm{ppb}\end{array}$ & Ma et al. [35] \\
\hline \multicolumn{5}{|l|}{ Metal oxide (MOX) } \\
\hline $\begin{array}{l}\mathrm{SnO}_{2}, \mathrm{CuO} \text { with photoresist and a } \\
\text { graphene sensing film }\end{array}$ & $3 \times 10^{2}-5 \times 10^{5 a}$ & NA & NA & Zhang et al. [63] \\
\hline $\begin{array}{l}\text { Nanostructured Sn oxide-based } \\
\text { porous materials doped with Zn }\end{array}$ & $8-500^{\mathrm{a}}$ & 1 & $\begin{array}{l}\text { At } \mathrm{RH}=60 \% \text {, the LOD increases from } \\
8 \text { to } 50 \mathrm{ppb}\end{array}$ & \\
\hline \multicolumn{5}{|l|}{ Electrical Impedance (EI) } \\
\hline $\begin{array}{l}\text { Macroporous } \mathrm{TiO}_{2} \text {-based semicon- } \\
\text { ductor-type sensor }\end{array}$ & $5-50^{a}$ & $1^{\mathrm{a}}$ & $\begin{array}{l}\text { At } \mathrm{RH}=50 \% \text {, the impedance of the } \\
\text { sensor increases }\end{array}$ & Liu et al. [34] \\
\hline Nanostructured zinc oxide ( $\mathrm{ZnO}$ & $5-1000^{a}$ & 18 & & Kannan and Saraswathi [27] \\
\hline
\end{tabular}

further increase their sensitivity, stability and selectivity toward formaldehyde by implementing their algorithm to convert the raw sensor outputs into units of concentration $[15,16]$. Other advantages of El sensors are: the ability to be miniaturized, high sensitivity, low cost of electrode mass production, and ease of implementation [16]. Examples of commercially available El and MOX sensors are reported in Table S. 1 in the Supplementary Information (SI) section. The moderate cost, availability, ease of use, user-friendly software, data accessibility, low limit of detection, and high accuracy are the reasons for the selection of uHoo monitors for this project. Moreover, the ability of measuring simultaneously the total volatile organics, excluding formaldehyde and using a separate MOX sensor, is appealing for environments, such as a gross anatomy laboratory, where formaldehyde is one of the volatiles present.

While the references regarding the implementation of a low-cost sensor are numerous, few studies are dedicated to their evaluation $[10,33,44]$ due to the high expenses connected to the NIOSH 2016 method and in the dangers linked to the use of high levels of formaldehyde.

In this project, an El sensor is evaluated under laboratory-controlled environmental conditions. Additionally, these low-cost multi-channel sensors were placed in a gross anatomy laboratory and used to record in real time the concentration levels of formaldehyde. The accuracy of the low-cost monitors was achieved through the comparison with the standard method NIOSH 2016. Furthermore, exposure levels of formaldehyde for embalmers, medicine students, and other operators are reported for each activity analyzed.

\section{Materials and methods}

\subsection{Formaldehyde low-cost sensor}

The formaldehyde sensor is embedded in a low-cost multi-channel monitor (uHoo, uHoo Limited) that is able to measure other indoor pollutants, as detailed in the $\mathrm{SI}$ and in a previous Ref. [3]. For example, one sensor contained in uHoo monitors is dedicated to the detection of volatile organic compounds (VOCs). Both VOC and formaldehyde sensors are El and, while the first responds to all the volatiles excluding formaldehyde, the second one involves algorithms that aim to detect only formaldehyde. The similarity between these two sensors is expected to raise interferences. A series of algorithms have been developed by uHoo to transform the raw data from each 
formaldehyde and VOC sensors into data showing measurements of these two pollutants. These two sensors produce readings each minute and auto-calibrate every $24 \mathrm{~h}$. The auto-calibration consists in an estimation of the exposure levels that the sensors are exposed to for a prolonged time. Therefore, the software updates and becomes more accurate to the prolonged specific conditions of the indoor environment. Due to this frequent auto-calibration, a period of "warm-up" of the formaldehyde and VOC lowcost sensors is needed for a reliable measurement. More details on the VOC sensor are reported in a previous publication [3].

The commercially available uHoo formaldehyde sensor can reach level of $2000 \mathrm{ppb}$. However, for the tests shown in this publication, the sensor was set to have a maximum of $10,000 \mathrm{ppb}$. The manufacturer claims a resolution of $1 \mathrm{ppb}$ and an accuracy of $30 \mathrm{ppb}$. Potential interferences to a formaldehyde sensor are VOCs, as shown in previous references [51, 62]. While uHoo multi-channel monitors including a TVOC sensor are commercially available, the version used in this study, including a formaldehyde sensor, is not on the market at the moment and it was designed and built for this research project.

\subsection{Low-cost formaldehyde sensor's laboratory evaluation}

The low-cost formaldehyde sensor is evaluated using the setup shown in Fig. 1. Three sensors were placed in a $40 \mathrm{~L}$ enclosure $(19.68 \times 15.75 \times 7.87 \mathrm{~cm})$. The location of the sensors was selected arbitrarily. However, for the same level of expected concentration of formaldehyde, the maximum variability of the sensors reading was $13 \%$. A fan was used to accelerate the distribution of the evaporating gas inside the enclosure. The enclosure was air-tight; even the connections to the low-cost sensors and to the fan were sealed. Seven quantities of formalin solution were inserted in the enclosure to generate a broad range of mass levels. Two syringes ( $1 \mu \mathrm{l}$ and $10 \mu \mathrm{l}$ ) were used to quantify the formalin solution that was inserted in the enclosure

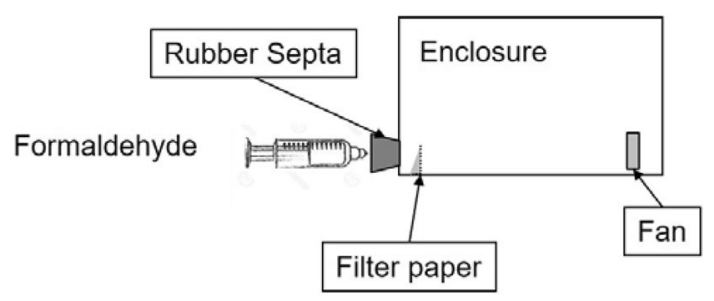

Fig. 1 Experimental system used to validate the formaldehyde readings of the tested low-cost multi-channel monitors. Three monitors are placed at different locations in the enclosure. One $\mathrm{NIOSH}$ sampler is placed on the side of one of the three monitors through a rubber septum. The quantity of formalin solution inserted in the enclosure quickly evaporates due to high vapor pressure $[2,18]$ and, if not, was then deposited on a filter paper.

A reference method was used to validate the accuracy of the low-cost formaldehyde sensor readings. The reference method selected was NIOSH 2016, a Federal Reference Method (FRM) [40]. Formaldehyde is trapped on an active sorbent impregnated with 2,4-dinitrophenylhydrazine (2,4-DNPH). Per each concentration selected, one sorbent tube was taped close to the collection point of one low-cost sensor. To evaluate the reproducibility, the same experiment was repeated twice for some of the concentrations studied. Active collection was selected since OSHA advises that passive samplers should not be used for sampling circumstances concerning formalin solutions because of an underestimation in the presence of reaction products of formaldehyde and methanol (a formalin additive) [32]. A Gillian GilAir pump was connected with the glass tube NIOSH sampler. The total flow rate was calibrated with a flow meter and set at $0.2 \mathrm{~L} / \mathrm{min}$. The bias error of a Gillian GilAir pump is estimated to be $10^{-2} \mathrm{~L} /$ min. By propagating this uncertainty, the error involved in the formaldehyde measurements is considered irrelevant.

To ensure a steady-state formaldehyde concentration inside the chamber, an equal amount of clean air was inserted while collecting even though the collection was activated only when the formaldehyde readings of the low-cost sensors reached a stable value $( \pm 5 \%$ of variation). The collection time was set to $25 \mathrm{~min}$. Analysis is then conducted in the laboratory by high-performance liquid chromatography and ultraviolet detection at $350 \mathrm{~nm}$.

The formalin solution used ( $37 \mathrm{wt} \%$ in water) was stabilized with methanol-approximately $10-15 \%$, which can interfere in the measurements of formaldehyde achieved by using low-cost sensors. The interference of methanol to the formaldehyde sensor was verified by inserting pure methanol in the enclosure and recording the formaldehyde sensors readings. Since the formalin solution contains a large content of water, the impact of humidity to the measurement of formaldehyde of the low-cost sensors is quantified (Table S. 1 in the SI).

The effect of other pollutants on the low-cost formaldehyde sensors has been tested. For example, phenol, which is the most common pollutant in gross anatomy laboratories besides formaldehyde, was inserted in the system shown in Fig. 1. Other substances that were involved in experiments conducted in the gross anatomy laboratory were Infutrace, cadaver's leakage, and embalming fluid. All these substances were also introduced in the system shown in Fig. 1. In the case of phenol, due to its presence in every activity in a gross anatomy laboratory, ten different quantities were injected. Moreover, five different tests 
were conducted per each quantity inserted. For the other substances, four-to-five different quantities were injected and each test was repeated five times.

\subsection{Gross anatomy laboratory formaldehyde measurements}

Levels of formaldehyde were measured in the gross anatomy laboratory of the University of British Columbia. The main expected reason of formaldehyde emissions in a morgue is the liquid used for embalming the body which is composed of $71 \%$ 2-propanol, $20 \%$ propylene glycol, $5 \%$ formalin [1.8\% formaldehyde], and $4 \%$ phenol. In addition, Infutrace, a liquid, with unknown composition (possibly containing a small portion of formaldehyde), is used for post-treatments of the embalmed body to reduce formaldehyde emissions. When inserting Infutrace in an embalmed body, embalming liquids can leak. The embalming liquid, the embalming liquid deprived of formalin, Infutrace, and the leakages from a decomposing body were inserted in the same experimental system shown in Fig. 1 in order to verify a possible interference with the formaldehyde sensor contained in uHoo monitors.

Figure 2 shows the layout of the University of British Columbia gross anatomy laboratory. The locations at which measurements were taken were labeled with letters; $A, B, C, D$, and $E$ indicate five locations in the dissection laboratory, $\mathrm{F}$ the morgue where the embalming procedure commonly takes place, $\mathrm{G}$ the storage room, and $\mathrm{H}$ the hallway. The sensors were placed close to a wall due to the need of a constant electrical supply. Air Handling Unit (AHU) numbers 7 and 5 are used for the gross anatomy laboratory and for the morgue, respectively. Both AHU supplies $100 \%$ of outdoor air with a single supply air fan, cooling coil, heat recovery and humidify coil. The supply fan is operated through Variable Speed Drive (VSD) unit working at 90 and $95 \%$ for AHU-7 and-5, respectively. By measuring,

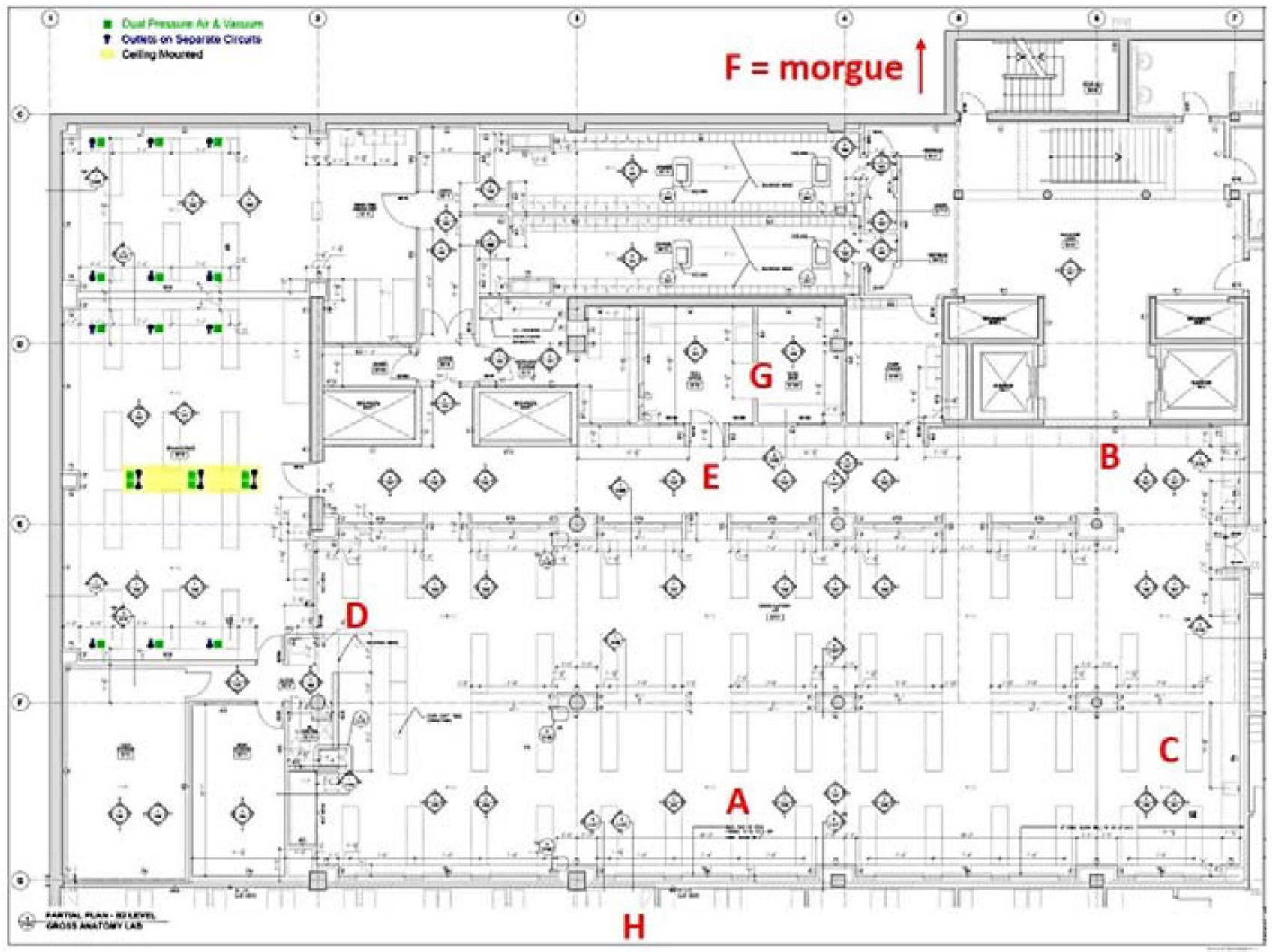

Fig. 2 Image of the layout of the University of British Columbia gross anatomy laboratory. The analyzed rooms and locations were labeled with a letter. $A, B, C, D$, and $E$ relate to five locations in the dissection laboratory opened space; $F$ the morgue, and $G$ the storage room 
with an anemometer, the air velocity in the ducts of the systems, the air volume per time can be derived. Based on the last maintenance report, about 36,100 and $11,000 \mathrm{cfm}$ are supplied by AHU-7 and AHU-5, respectively. Therefore, air ventilation of 15 and 20 rooms per hour occurs in the gross anatomy laboratory and in the morgue, respectively. Even though humidity shows a mild effect on the low-cost formaldehyde sensor used (see SI), more tests would be needed to confirm this trend. Therefore, humidity was recorded, by using a thermo-hygrometer (Omega HHF710) throughout the experiments in the morgue. The humidity levels vary from 27 to $32 \%$ depending on the location within the gross anatomy laboratory.

A total of 20 activities were studied. The readings of low-cost sensors were compared with the NIOSH 2016 for 12 activities due to limitations in the expenses. For the same reason, for one activity, the average levels of phenol were recorded using NIOSH 2546 [49]. Details on the activities measured are shown in Table 2 . These activities were considered since they are expected to generate the highest levels of toxic indoor pollutants. Analyzing these activities can show the impact to the embalmers, such as embalming procedure and mixing fluids, and to the medical students, such as the gross anatomy laboratory.

The activities shown in Table 2 were selected also for the following reasons. A typical embalming procedure takes about $4 \mathrm{~h}$ of hands-on work, including the Infutrace infiltration; on a yearly average, this process is done twice per week. Mixing fluid takes about $15 \mathrm{~min}$ and is done once or twice per month. Brain injection takes about $2 \mathrm{~min}$ and is done for every cadaver, so approximately 100 times per year or twice per week. At the University of British Columbia, the Medical and Dentistry students' time in the laboratory depends on their year of studies. First-year students have approximately 43 scheduled hours in the laboratory over two terms, while second-year students have about 32.5 scheduled hours.

\section{Results and discussion}

\subsection{Low-cost formaldehyde sensor's laboratory evaluation}

The formaldehyde detection is the main innovation of the last version of uHoo monitors. Due to the design of the formaldehyde and TVOC channels, some degree of cross-talk/ interference is expected. Figure 3a shows the interferences of volatile compounds to the readings of formaldehyde sensors included in uHoo monitors. Error bars indicate the differences in readings of the three low-cost formaldehyde and VOC sensors. Due to the interference of methanol to the formaldehyde readings of uHoo sensors, the data are treated as "without methanol correction" if not corrected
Table 2 Details on the activities recorded with the low-cost sensors

\begin{tabular}{|c|c|c|c|c|}
\hline$\#$ & Activity & NIOSH 2016 & $\begin{array}{l}\text { Collection time } \\
\text { (min) }\end{array}$ & Location \\
\hline 1 & No activity & $x$ & 15 & A \\
\hline 2 & No activity & $x$ & 15 & $\mathrm{~F}$ \\
\hline 3 & No activity & $x$ & 15 & G \\
\hline 4 & One opened bag ( 2 meters apart) & $x$ & 15 & A \\
\hline 5 & One opened bag (placed at A) & - & 10 & B \\
\hline 6 & One opened bag (placed at A) & - & 15 & $\mathrm{C}$ \\
\hline 7 & One opened bag (placed at A) & - & 30 & $\mathrm{D}$ \\
\hline 8 & One opened bag (placed at A) & - & 30 & $E$ \\
\hline 9 & Two opened bags (placed at A) & - & 30 & A \\
\hline 11 & Above an opened body & $x$ & 15 & $A$ \\
\hline 12 & 240 students and 32 opened bags & $x$ & 20 & A \\
\hline 13 & 240 students and 32 opened bags & - & 20 & $E$ \\
\hline 14 & 240 students and 32 opened bags & - & 20 & $\mathrm{C}$ \\
\hline 15 & 240 students and 32 opened bags & - & 20 & $\mathrm{H}$ \\
\hline 16 & 350 students and 73 opened bags & x (NIOSH 2546) & 20 & $\mathrm{C}$ \\
\hline 17 & Mixing embalming fluids & $x$ & 10 & $\mathrm{~F}$ \\
\hline 18 & Brain injection & $x$ & 7 & $\mathrm{~F}$ \\
\hline 19 & Embalming procedure & $x(2)$ & 10 & $\mathrm{~F}$ \\
\hline 20 & Infutrace treatment & $\mathrm{x}$ & 10 & $\mathrm{~F}$ \\
\hline
\end{tabular}

For some activities, the readings of the low-cost sensors are compared with NIOSH 2016. NIOSH 2546 was used to record the average levels of mass of phenol 


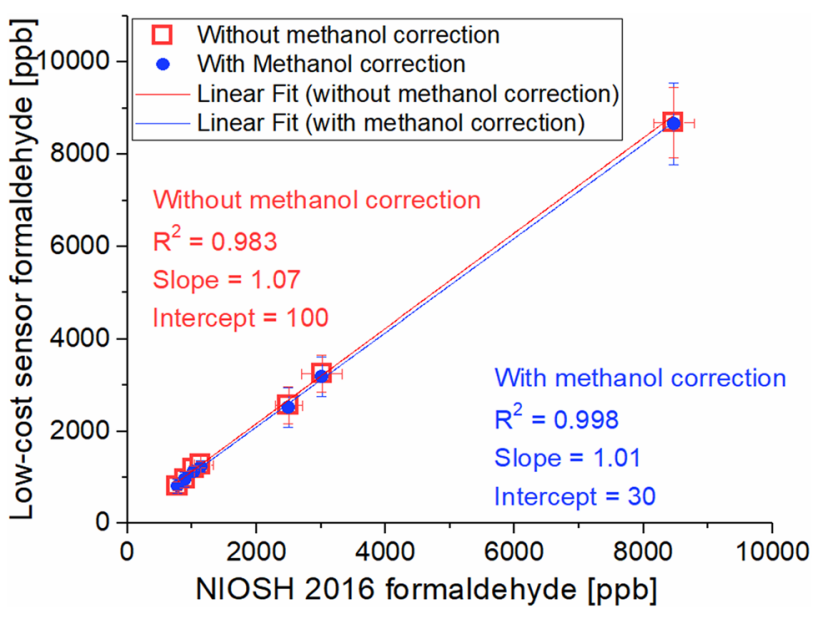

Fig. 3 Comparison between the $\mathrm{HCHO}$ concentration levels recorded using the NIOSH 2016 and using the tested low-cost multi-channel sensors. The readings of the low-cost monitors were averaged for the collection time used for the NIOSH 2016

and "with methanol correction" if raw data are corrected based on the results obtained in Fig. 3a. Using the linear equation shown in Fig. 3a, the interference of methanol at different quantities of formaldehyde recorded can be measured. Therefore, this quantity is later subtracted for the laboratory tests, where methanol is a fixed component (Fig. 3b).

On average, the low-cost sensor readings were less than 14\% higher than the FRM NIOSH 2016 results (Fig. 3b). It appears that high concentrations of formaldehyde show higher standard deviations indicating that the homogeneity in the enclosure at high concentration is lower in respect with lower concentrations. The differences between the uHoo formaldehyde sensors and the $\mathrm{NIOSH}$ 2016 sampler can be due to different interferences. The cross-interference between VOC and formaldehyde sensors is considered minor, as shown in the SI. The interference of other gases to the formaldehyde sensor can be thus, a plausible reason. Since the formaldehyde source used in the tests contained methanol, its interference is verified. The linear regression of this interference generates a slope of 0.26 and an intercept of about 41 , which indicate a relatively low impact of methanol to the formaldehyde readings. At concentrations below 500 ppb, methanol generates an even smaller increase in the formaldehyde measurements of uHoo (Fig. 3). Thus, the methanol contained in the solution used for the laboratory test was assumed not to substantively interfere with the formaldehyde readings of the tested low-cost sensors. However, at the average concentration seen in these tests, about $2500 \mathrm{ppb}$ formaldehyde, the methanol contributed an interference of $5 \%$ to the formaldehyde sensor. With a correction factor calculated from the data shown in Fig. 3a, this interference can be corrected for, making uHoo readings less than $6 \%$ higher than the NIOSH 2016 results.

To verify the interference of other gases to the formaldehyde sensor, a few compounds, such as phenol, embalming fluid, and Infutrace, are placed in the same experimental system shown in Fig. 1 (results shown in Fig. 4). In Fig. 4, the readings of the VOC and the formaldehyde low-cost sensors embedded in uHoo monitors are compared during the exposure of common pollutants in a gross anatomy laboratory, such as phenol (Fig. 4a), or to common volatiles used in embalming procedures, such as embalming fluid, Infutrace, and body leakages (Fig. 4b). Error bars concerning the measurements of reference
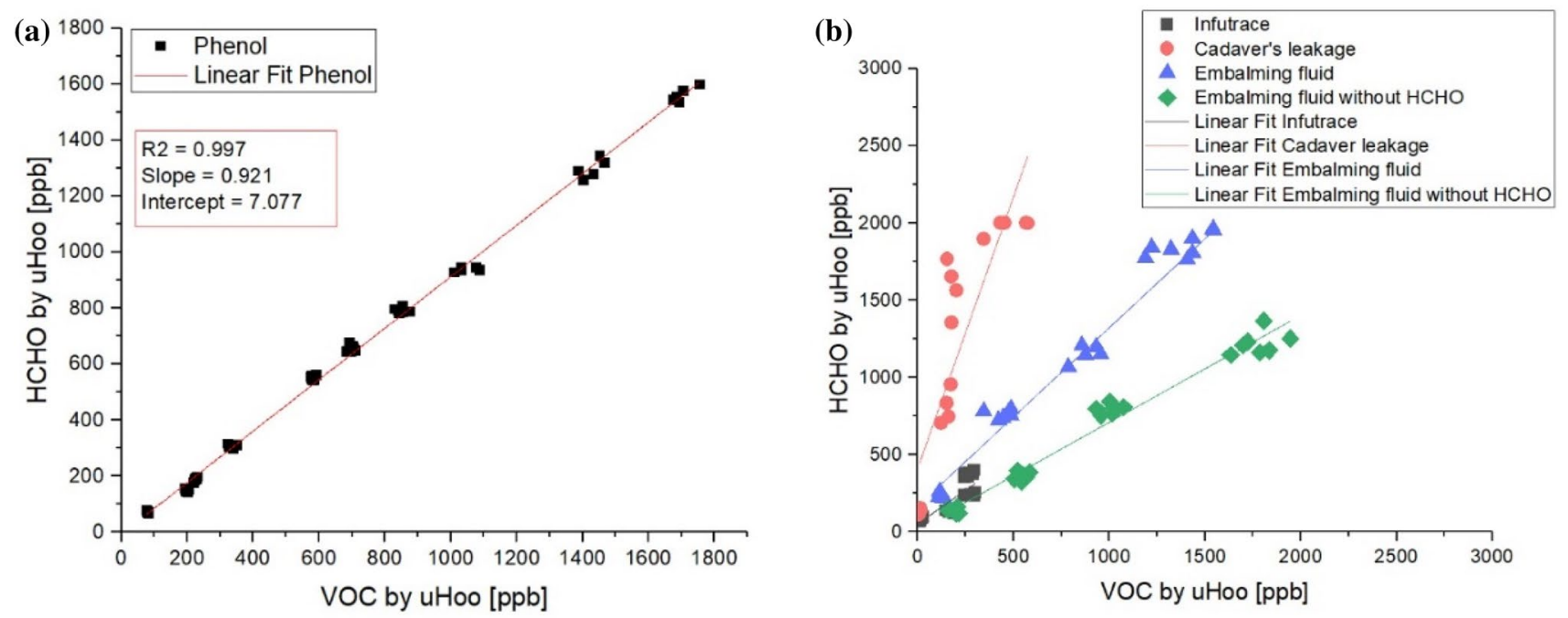

Fig. 4 Comparison between the $\mathrm{HCHO}$ and the TVOC sensors is shown when monitors are placed in the experimental system explained in Sect. 2.2 and exposed to phenol (a), Infutrace, a cadaver leakage, the embalming fluid, and the embalming fluid without $\mathrm{HCHO}$ (b) 
methods are derived by the uncertainty propagation of bias errors involved with the pump used for collection and the analytical technique. Phenol is an indoor gas highly present in a gross anatomy laboratory and is expected to contribute to an interference to the formaldehyde sensor. Moreover, previous references indicate that phenol is the major volatile organic components, besides formaldehyde, present in a gross anatomy laboratory. Activities like dissection and embalming, typical of a morgue, are shown to produce mostly formaldehyde and phenol $[13,58]$. It is expected that phenol should activate a response only of the low-cost VOC sensor. However, due to the similarities in the formaldehyde and VOC low-cost sensor, phenol can be a source of cross-interference. Figure 4 shows, in fact, that phenol generates a positive interference to both the VOC and the formaldehyde sensors. This correlation indicates that other alkanes or alcohol can generate a positive interference to the low-cost formaldehyde sensor. Even though low-cost formaldehyde sensors are supposed to target solely formaldehyde, similar chemical compounds, such as phenol, can generate a false response of the lowcost formaldehyde sensor. This is a great limitation for the low-cost sensor used and, possibly, of other similar lowcost formaldehyde sensors.

The leakage from the body generated higher levels of formaldehyde, identifying a possible positive interference of the formaldehyde sensor when exposed to VOC with much higher content. Furthermore, the linearity of regression coefficient is similar when comparing the formaldehyde and the VOC readings of the uHoo monitors when exposed to gases evaporating from a common embalming fluid and to the embalming fluid deprived by all the formaldehyde. Thus, it is expected that the low-cost sensors can read higher values than the reference methods when exposed to activities such as embalming and dissection laboratory [31].

\subsection{Gross anatomy laboratory formaldehyde measurements}

As shown in Table 2, NIOSH 2016 was used as a comparison to the real-time readings of uHoo sensors for selected activities. Figure 5 shows the formaldehyde levels measured per different activities by using both the FRM method, the NIOSH 2016, and the low-cost sensors, uHoo. Activities 1 and 2 shown in Table 2 are not reported in Fig. 5 since the detection limit (NIOSH 2016) of $0.1 \mu \mathrm{g}$ was not reached. The readings obtained from uHoo were averaged for the same time span used for the NIOSH collection.

For all the activities considered, the tested low-cost sensors (crosshatched green columns in Fig. 5) show higher values of formaldehyde compared to the NIOSH 2016 (plain red columns in Fig. 5). The low-cost sensors

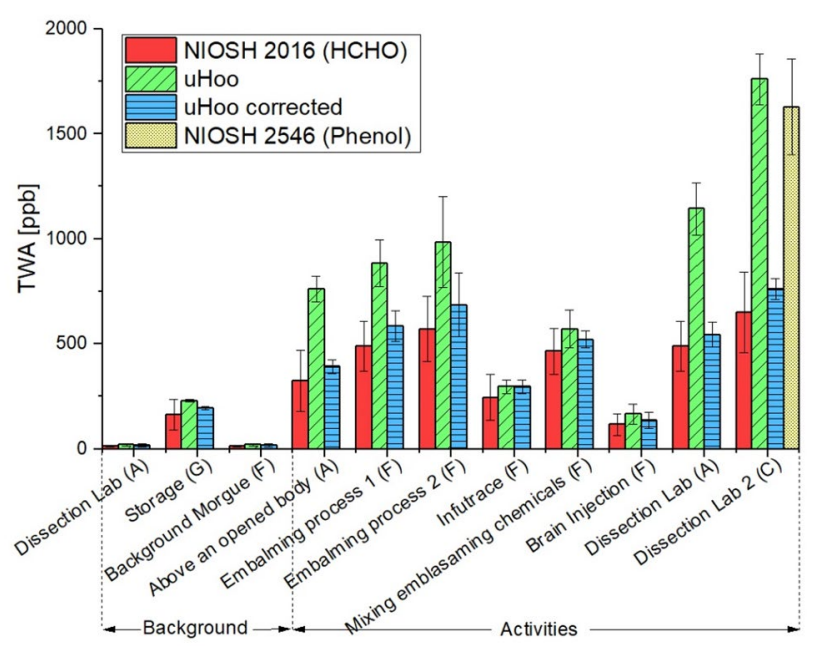

Fig. 5 Comparison between the HCHO Federal Reference Method (NIOSH 2016), red columns, and real-time low-cost sensors reading, green and sparse lined columns. The blue horizontal lined columns indicate the uHoo reading corrected by phenol interference. The correction factor is obtained using the linearity of regression shown in Fig. 3a. In addition, emissions of phenol are recorded with the related Federal Reference Method (NIOSH 2546) and shown in yellow square lined column. Locations at which the measurement were taken are shown in brackets

recorded, for the same activities, the presence of volatile organic compounds, as shown in the SI. The dotted yellow square lined column in Fig. 5 identifies the level of phenol recorded using NIOSH 2546. Phenol is selected since it is the volatile organic compound with the highest content in an embalming fluid. This result confirms the conclusions achieved by the data shown in Fig. 4. The blue horizontally lined bar in Fig. 5 shows the lowcost sensor reading corrected using the linearity regression shown in Fig. 4a. Based on the linear curve shown in Fig. 4a, the low-cost formaldehyde sensors show a positive interference with different quantities of phenol. The regression shown in Fig. 4 a determines a correlation between formaldehyde and phenol. Furthermore, in Fig. 5 , this positive interference is subtracted to the total formaldehyde readings of the low-cost sensors (crosshatched green columns). By introducing this correction, the low-cost sensor readings show an average difference of $9 \%$ with respect to NIOSH 2016.

Table 3 shows the 8 -hour TWA by using $15 \mathrm{~min}$ as collection time, and the highest instantaneous reading of formaldehyde emissions recorded by the validated low-cost sensor per each activity tested and shown in Table 2. The standard deviations shown in Table 3 were obtained by considering different low-cost sensors and different locations. Here, the values that exceed the TLVSTEL, $0.3 \mathrm{ppm}$, are shown in italic, while the values that exceed the NIOSH ceiling limit, 0.1 ppm, are in bold. The 
Table 3 STEL readings ( $15 \mathrm{~min}$ ) and the ceiling (highest instantaneous reading) of formaldehyde recorded by uHoo per each activity

\begin{tabular}{|c|c|c|c|}
\hline \# & Activity & STEL [ppb] & Ceiling [ppb] \\
\hline 1 & No activity (Location A) & $13.5 \pm 2.5$ & $53 \pm 17.1$ \\
\hline 2 & No activity (Location G) & $39 \pm 9.8$ & $147 \pm 12.3$ \\
\hline 3 & No activity (Location F) & $14.5 \pm 3.7$ & $83 \pm 37.6$ \\
\hline 4 & One opened bag (about 2 meters of distance) & $92 \pm 23$ & $203 \pm 34$ \\
\hline 5 & One opened bag placed at A (Location B) & $76 \pm 11$ & $138 \pm 9.7$ \\
\hline 6 & One opened bag placed at A (Location C) & $103 \pm 33$ & $183 \pm 65$ \\
\hline 7 & One opened bag placed at A (Location D) & $93 \pm 7.5$ & $146 \pm 34$ \\
\hline 8 & One opened bag placed at A (Location E) & $64 \pm 11$ & $111 \pm 10$ \\
\hline 9 & Two opened bags place at A (Location D) & $273 \pm 32$ & $498 \pm 21$ \\
\hline 11 & Above an opened body & $395 \pm 96$ & $713 \pm 78$ \\
\hline 12 & 240 students and 32 opened bags (Location A) & $545 \pm 112$ & $1765 \pm 234$ \\
\hline 13 & 240 students and 32 opened bags (Location E) & $826 \pm 145$ & $1334 \pm 276$ \\
\hline 14 & 240 students and 32 opened bags (Location C) & $545 \pm 112$ & $1265 \pm 234$ \\
\hline 15 & 240 students and 32 opened bags (Location $\mathrm{H}$ ) & $23 \pm 5.5$ & $54 \pm 3.4$ \\
\hline 16 & 350 students and 73 opened bags (Location C) & $742 \pm 256$ & $1856 \pm 453$ \\
\hline 17 & Mixing embalming fluids & $528 \pm 39$ & $1528 \pm 324$ \\
\hline 18 & Brain injection & $167 \pm 46$ & $274 \pm 75$ \\
\hline 19 & Embalming procedure & $535 \pm 91$ & $2177 \pm 138$ \\
\hline 19 & Embalming procedure [2] & $636 \pm 54$ & $1376 \pm 234$ \\
\hline 20 & Infutrace treatment & $335 \pm 54$ & $1180 \pm 184$ \\
\hline
\end{tabular}

The standard deviations are obtained by comparing the readings achieved by using different low-cost monitors. The spikes relate to 1-min reading. In the STEL column, italic values exceed the TLV-STEL of $0.3 \mathrm{ppm}$. In the ceiling column, bold values exceed the NIOSH REL ceiling of $0.1 \mathrm{ppm}$ data shown in Table 3 are adjusted for the positive interference of phenol.

Figure 6 shows the comparison between the real-time measurements obtained using the low-cost sensors and time-averaged results attained using $\mathrm{NIOSH} 2016$. Figure 6 concerns two cases of dissection laboratory, as shown in

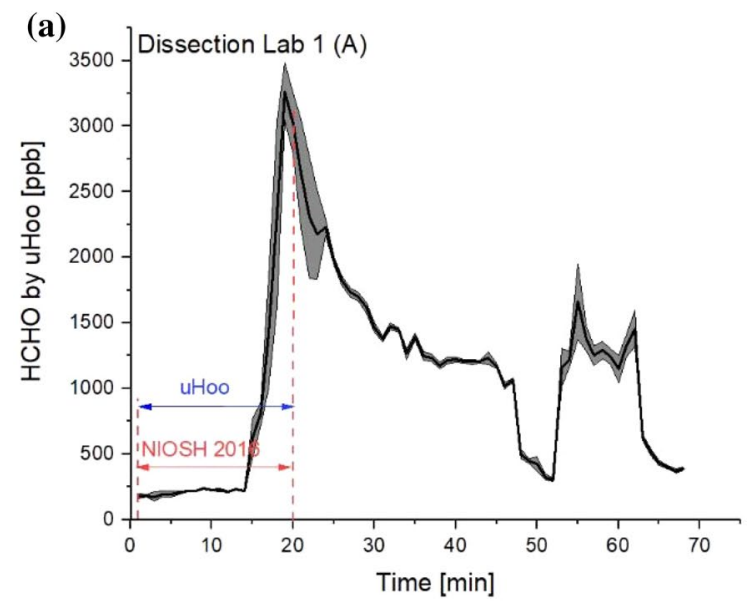

Fig. 6 Real-time readings for the activity of dissection laboratory (a, b). The results achieved using the low-cost monitor, uHoo, and the Federal Reference Method NIOSH 2016 are shown. a Relates to the activity dissection laboratory 1 , while $\mathbf{b}$ to the activity called dis-
Table 2. In Table 3, in 8 out of 20 activities, the 15-min TWA values do exceed the TLV-STEL criteria, while the ceiling values for almost every activity ( 17 out of 20 ) are above the $\mathrm{NIOSH}$ ceiling limit. Furthermore, the differences between the ceiling and the 15-min TWA values show the importance of real-time monitoring of formaldehyde in a gross

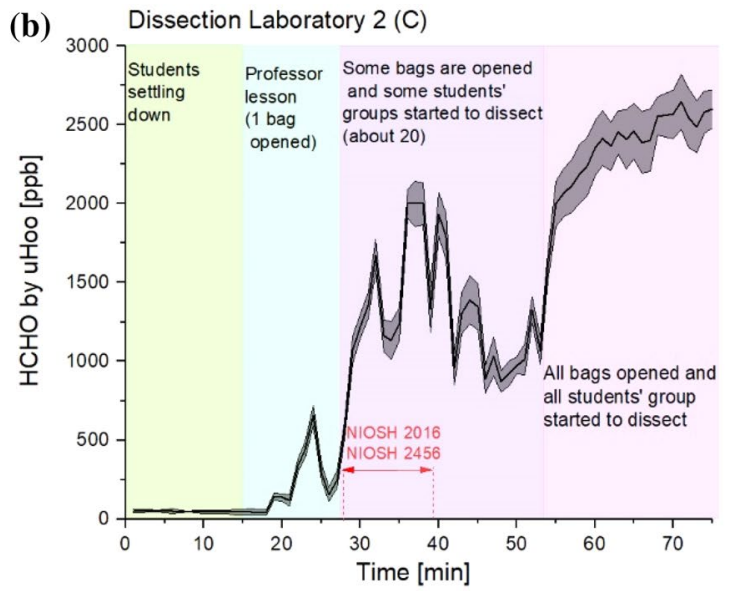

section laboratory 2. Brighter areas identify the standard deviation obtained by using different uHoo monitors. Location at which the low-cost sensors are placed in brackets 
anatomy laboratory. Examples of real-time data readings are shown in both Fig. 6 and Fig. 7.

In Fig. 6, the dissected area concerned the oral cavity. In this case, the recording started at the beginning of the dissection laboratory, when usually the professor takes about 10 min to explain the theory regarding the area of the body to dissect. At this moment, only one bag, the one used by the professor, is opened. After about $15 \mathrm{~min}$, the students started to practice; at first, some of the bags are opened and after 10-15 min, all the bags are opened (Fig. 6b). The curve in Fig. 6a continues up to $70 \mathrm{~min}$. Between the 45th and the 53rd min, the low-cost sensors were placed far from the body bags showing similar levels to the initial minutes. This level of details in correlating formaldehyde, along with other dangerous TVOC, levels and the activities in the gross anatomy laboratory would be impossible by using the reference methods.

During the other activities, other spikes in formaldehyde levels were recorded (Fig. 7a, b). In Fig. 7, the activities recorded in location $F$, in the morgue, are shown. Data shown in Figs. 6a, b, and 7a, b were not corrected using the phenol interference correction factor determined by Fig. 3a.

In Fig. 7, the highest spike is seen in the embalming procedures. In the first embalming procedure, the first peak identifies the starting moment of the insertion of the embalming fluid in the cadaver, while the second lower peak can identify a possible spill. In the second embalming procedure, similar peaks are seen. However, in this case a higher peak is seen when a spill of the embalming fluid happened. The difference between two embalming procedures shows the strong influence on the formaldehyde emissions of the embalmer's movements. When considering the spikes, the instantaneous formaldehyde concentration can reach about $3 \mathrm{ppm}$. A common embalming procedure contains about 15 min of levels higher than $0.1 \mathrm{ppm}$ (Fig. 7b). Considering that, on average, three embalming procedures occur every week, an embalmer spends on average $39 \mathrm{~h}$ per year at levels of formaldehyde much higher that $0.1 \mathrm{ppm}$. By adding other activities, such as Infutrace and brain injection and assistance to dissection laboratories, an embalmer could spend on average more than $60 \mathrm{~h}$ per year at levels of formaldehyde much higher than $0.1 \mathrm{ppm}$.

\section{Conclusion}

Formaldehyde is known to be an indoor pollutant dangerous to human health. Common liquids used for the embalming procedure contain more than $37 \%$ formalin liquid. Embalmers, medical students, and doctors are exposed to the vapors emitted by an embalmed body for an average of few hours per week. This project verifies the importance of real-time measurements of formaldehyde in a gross anatomy laboratory. Totally, 17 of the 20 tasks sampled showed ceiling levels exceeding the NIOSH REL ceiling of $0.1 \mathrm{ppm}$, with 7 of those tasks having levels more than 10 times in excess. Specifically, the dissection laboratory showed levels around $1 \mathrm{ppm}$ for more than $1.5 \mathrm{~h}$. Considering embalmers spend about $200 \mathrm{~h}$ per year in embalming a cadaver, the levels

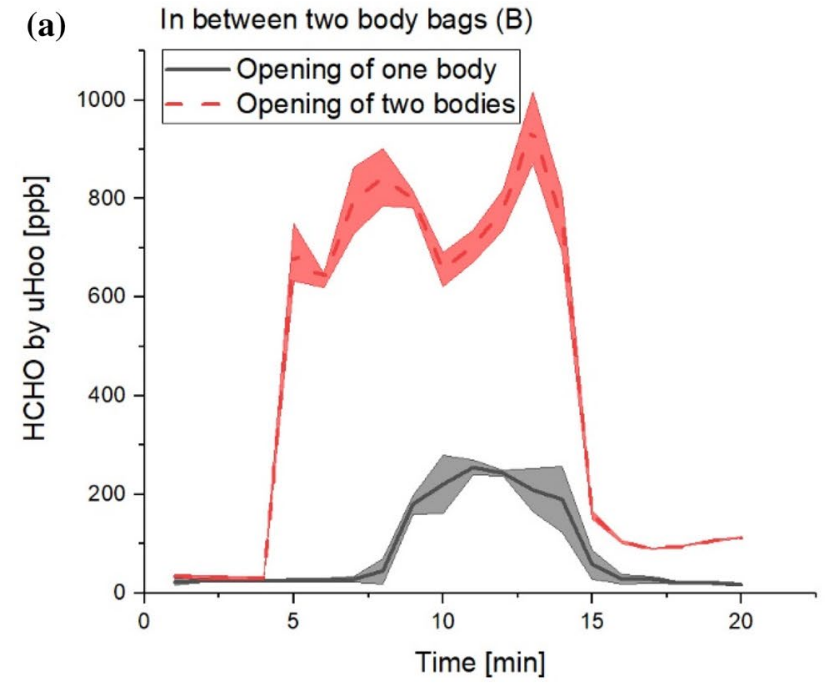

Fig. 7 In (a), the real-time measurements obtained by placing the monitors in the same location and while one or two bags were opened. Sensors were located in the dissection laboratory at the location $B$ real-time measurements of the levels in the morgue. In

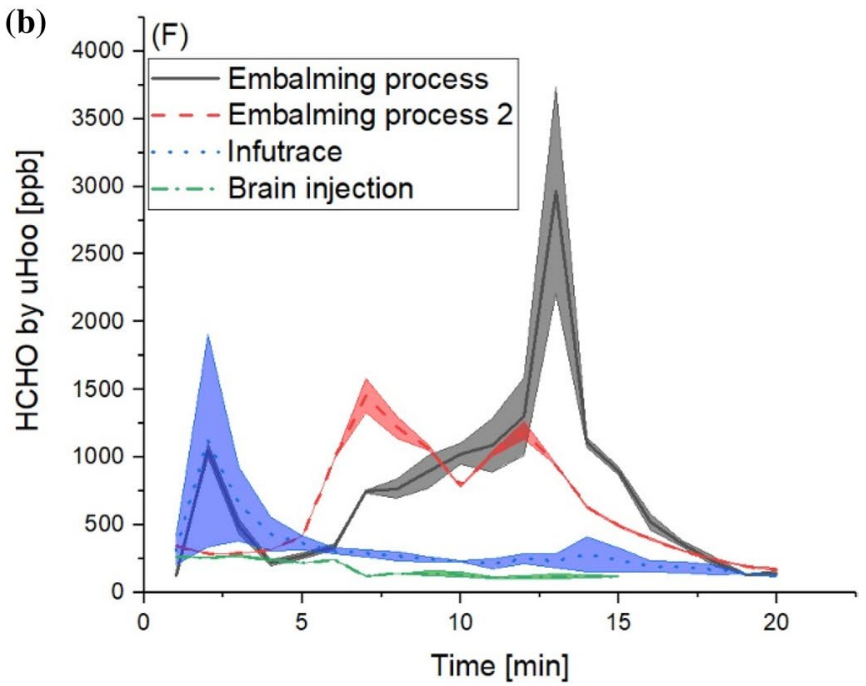

(b), the activities considered are: brain injection, two embalming processes, and the injection of Infutrace. These tests were conducted in the morgue (Location F) 
of formaldehyde recorded in real time generate a high concern for the embalmer and a stricter protection procedure should be considered to reduce the long-term formaldehyde exposure.

Real-time readings were reached by using low-cost formaldehyde sensors which include some uncertainties, such as the influence of other VOCs, temperature, and humidity, long-term performance stability, and detection limit. For example, an interference between the volatile organic component and the formaldehyde sensor is recorded generating an overestimation of the formaldehyde levels by the real-time low-cost sensors. Primarily, the overestimation includes reading of phenol, another toxic gas and the major component of the embalming fluid used in the gross anatomy laboratory. In addition, the interference of phenol to the formaldehyde lowcost sensor indicates that other aldehydes or alcohols could generate a similar effect. Therefore, the approach shown here can be used only for a gross anatomy laboratory, where the major indoor pollutants are phenol and formaldehyde. In other environments, determining the other types of volatiles present can be fundamental to estimate the actual levels of formaldehyde recorded by the low-cost sensor.

By adjusting uHoo readings for the positive interference of phenol, the recorded values differ from NIOSH 2016 by less than $20 \%$. These sensors can show unexpected rises of formaldehyde levels due to the number of bags opened in a dissection laboratory, mistakes in the embalming procedures, or spills of the embalming fluids. The use of these sensors can generate more taskbased information and facilitate a more targeted sampling program, helping to prevent the risks involved with a long-term exposure to formaldehyde.

The main advantage of the low-cost sensors is the real-time measurements, as shown in Fig. 6. NIOSH 2016 and NIOSH 2546 samplers are commonly employed for 15-min STEL sampling or 8-h TWA sampling to compare the results with NIOSH TWA and STEL limits. By definition, their results are averaged over the sampling time. Real-time monitoring generates data each minute (sampling interval), facilitating comparison with ceiling limits and making it possible to correlate individual tasks to formaldehyde and other TVOC emissions. These monitors can show how each opened bag produces an increase in level of formaldehyde and TVOCs. Figure $6 \mathrm{~b}$ shows the real-time formaldehyde levels recorded in the dissection laboratory when one or two bags were opened. In both cases, real-time measurement can identify the exact moment at which the bags are opened.

Acknowledgements The authors would like to acknowledge Dr. Ben Loosley for suggesting useful improvements to the project and for accurately reviewing the manuscript and Prof. Steven Rogak for allowing the use of his facility, the Aerosol Laboratory at the University of British Columbia. Furthermore, we would like to thank uHoo for providing a customized version of their sensor.

\section{Compliance with ethical standards}

Conflict of interest The authors declare that they have no conflict of interest.

\section{References}

1. Allouch A, Guglielmino $M$, Bernhardt $P$, Serra $C A$, Le Calvé $S$ (2013) Transportable, fast and high sensitive near real-time analyzers: formaldehyde detection. Sens Actuators B Chem 181:551-558. https://doi.org/10.1016/j.snb.2013.02.043

2. Azhdarzadeh $M$, Shemirani FM, Ruzycki CA, Baldelli A, Ivey J, Barona D, Church T, Lewis D, Olfert JS, Finlay WH, Vehring R (2016) An atomizer to generate monodisperse droplets from high vapor pressure liquids. At Sprays 26(2):121-134. https:// doi.org/10.1615/atomizspr.2015011631

3. Baldelli A, Loosley B (2020, Fortcoming) Evaluation of the performance of a low-cost multi-channel monitor for indoor air quality. J Sens

4. Baldelli A, Rogak SN (2019) Morphology and Raman spectra of aerodynamically classified soot samples. Atmos Meas Tech 12(8):4339-4346. https://doi.org/10.5194/amt-12-4339-2019

5. Bastuck $M$, Puglisi $D$, Möller P, Reimringer W, Schütze $A$, Spetz AL et al (2017) Low-cost chemical gas sensors for selective formaldehyde quantification at ppb-level in the field. In: AMA Conference Proceeding Sensors. 10.5162/sensor2017/P5.4

6. Bradman A, Gaspar F, Castorina R, Williams J, Hoang T, Jenkins PL, McKone TE, Maddalena R (2017) Formaldehyde and acetaldehyde exposure and risk characterization in California early childhood education environments. Indoor Air 27(1):104-113. https://doi.org/10.1111/ina.12283

7. Burgos-Barragan $G$, Wit N, Meiser J, Dingler FA, Pietzke $M$, Mulderrig L, Pontel LB, Rosado IV, Brewer TF, Cordell RL, Monks PS (2017) Mammals divert endogenous genotoxic formaldehyde into one-carbon metabolism. Nature 548(7669):549. https ://doi.org/10.1038/nature23481

8. Checkoway H, Dell LD, Boffetta P, Gallagher AE, Crawford L, Lees PS, Mundt KA (2015) Formaldehyde exposure and mortality risks from acute myeloid leukemia and other Lymphohematopoietic Malignancies in the US National Cancer Institute cohort study of workers in Formaldehyde Industries. J Occup Environ Med 57(7):785. https://doi.org/10.1097/JOM.0000000000000466

9. Chen H, Mo J, Xiao R, Tian E (2019) Gaseous formaldehyde removal: a laminated plate fabricated with activated carbon, polyimide, and copper foil with adjustable surface temperature and capable of in situ thermal regeneration. Indoor Air 29(3):469-476. https://doi.org/10.1111/ina.12540

10. Chevallier E, Caron T, Belon C, Karpe P, Tran-Thi T, Colomb S, Bigay $Y$ (2012) Development of a formaldehyde chemical sensor for indoor air quantification: application in health and safety at work. In: Conf Vent Paris Fr

11. Chi CY, Chen HI, Chen WC, Chang CH, Liu WC (2018) Formaldehyde sensing characteristics of an aluminum-doped zinc oxide (AZO) thin-film-based sensor. Sens Actuators B Chem 255:30173024. https://doi.org/10.1016/j.snb.2017.09.125

12. Chung PR, Tzeng CT, Ke MT, Lee CY (2013) Formaldehyde gas sensors: a review. Sensors 13(4):4468-4484. https://doi. org/10.3390/s130404468 
13. Coleman R, Kogan I (1998) An improved low-formaldehyde embalming fluid to preserve cadavers for anatomy teaching. J Anat 192(3):443-446. https://doi.org/10.104 6/j.1469-7580.1998.19230443.x

14. Collier-Oxandale AM, Thorson J, Halliday $\mathrm{H}$, Milford J, Hannigan M (2019) Understanding the ability of low-cost MOx sensors to quantify ambient VOCs. Atmos Meas Tech 12(3):14411460. https://doi.org/10.5194/amt-12-1441-2019

15. Cross ES, Williams LR, Lewis DK, Magoon GR, Onasch TB, Kaminsky ML, Worsnop DR, Jayne JT (2017) Use of electrochemical sensors for measurement of air pollution: correcting interference response and validating measurements. Atmos Meas Tech 10(9):3575-3588. https://doi.org/10.5194/ amt-10-3575-2017

16. Dai H, Gong L, Xu G, Li X, Zhang S, Lin Y, Zeng B, Yang C, Chen $G$ (2015) An electrochemical impedimetric sensor based on biomimetic electrospun nanofibers for formaldehyde. Analyst 140(2):582-589. https://doi.org/10.1039/C4AN02021A

17. Descamps MN, Bordy T, Hue J, Mariano S, Nonglaton G, Schultz E, Tran-Thi TH, Vignoud-Despond S (2012) Real-time detection of formaldehyde by a sensor. Sens Actuators B Chem 170:104-108. https://doi.org/10.1016/j.snb.2011.02.032

18. Ferraz-Albani LA, Baldelli $A$, Knapp CJ, Jäger W, Vehring R, Nobes DS, Olfert JS, Kostiuk LW (2017) Enhanced evaporation of microscale droplets with an infrared laser. J Heat Transf 139(1):10. https://doi.org/10.1115/1.4034486

19. Golden R (2011) Identifying an indoor air exposure limit for formaldehyde considering both irritation and cancer hazards. Crit Rev Toxicol 41(8):672-721. https://doi.org/10.3109/10408 444.2011.573467

20. Gosomji IJ, Omirinde JO, Hena SA, Wanmi N, Azeez IA (2018) Saturated salt solution an alternative reagent in reducing formaldehyde concentration in embalming. MOJ Anat Physiol 5(3):205-207. https://doi.org/10.15406/mojap.2018.05.00192

21. Guo XL, Chen Y, Jiang HL, Qiu XB, Yu DL (2018) Smartphonebased microfluidic colorimetric sensor for gaseous formaldehyde determination with high sensitivity and selectivity. Sensors 18(9):3141. https://doi.org/10.3390/s18093141

22. Hoang T, Castorina R, Gaspar F, Maddalena R, Jenkins PL, Zhang Q, McKone TE, Benfenati E, Shi AY, Bradman A (2017) VOC exposures in California early childhood education environments. Indoor Air 27(3):609-621. https://doi.org/10.1111/ina.12340

23. Hult EL, Willem H, Price PN, Hotchi T, Russell ML, Singer BC (2015) Formaldehyde and acetaldehyde exposure mitigation in US residences: in-home measurements of ventilation control and source control. Indoor Air 25(5):523-535. https://doi. org/10.1111/ina.12160

24. Jensen RP, Luo W, Pankow JF, Strongin RM, Peyton DH (2015) Hidden formaldehyde in e-cigarette aerosols. N Engl J Med 372(4):392-394. https://doi.org/10.1056/NEJMc1413069

25. Jiang Y, Liu Y, Chen M, Li M (2017) Assessment of formaldehyde pollution based on Weber exponent and perception of people's smell. Int J Environ Sci Technol 14(7):1469-1472. https://doi. org/10.1007/s13762-017-1249-7

26. Kalanjati VP, Prasetiowati L, Alimsardjono H (2012) The use of lower formalin-containing embalming solution for anatomy cadaver preparation. Med J Indonesia 21(4):203-207. https:// doi.org/10.13181/mji.v21i4.505

27. Kannan PK, Saraswathi R (2017) An impedance sensor for the detection of formaldehyde vapor using $\mathrm{ZnO}$ nanoparticles. J Mater Res 32(14):2800-2809. https://doi.org/10.1557/ jmr.2017.172

28. Kazemimanesh $M$, Dastanpour R, Baldelli A, Moallemi A, Thomson KA, Jefferson MA, Johnson MR, Rogak SN, Olfert JS (2019) Size, effective density, morphology, and nano-structure of soot particles generated from buoyant turbulent diffusion flames. J Aerosol Sci 132:22-31. https://doi.org/10.1016/j.jaero sci.2019.03.005

29. Keil CB, Akbar-Khanzadeh F, Konecny KA (2001) Characterizing formaldehyde emission rates in a gross anatomy laboratory. Appl Occup Environ Hyg 16(10):967-972. https://doi. org/10.1080/104732201300367227

30. Kennel L, Martin DM, Shaw H, Wilkinson T (2018) Learning anatomy through Thiel-vs formalin-embalmed cadavers: student perceptions of embalming methods and effect on functional anatomy knowledge. Anat Sci Educ 11(2):166-174. https://doi. org/10.1002/ase.1715

31. Kunugita N, Arashidani K, Yamato H, Tanaka I, Nakashima T, Kikuta A (2007) Evaluation of formaldehyde exposure during a gross anatomy dissection course. In: The 6th international conference on Indoor Air Quality, Ventilation \& Energy Conservation in Buildings IAQVEC Oct, pp 28-31

32. Lee EG, Magrm R, Kusti M, Kashon ML, Guffey S, Costas MM, Boykin CJ, Harper M (2017) Comparison between active (pumped) and passive (diffusive) sampling methods for formaldehyde in pathology and histology laboratories. J Occup Environ Hyg 14(1):31-39. https://doi.org/10.1080/15459 624.2016.1211284

33. Lewis A, Edwards P (2016) Validate personal air-pollution sensors. Nat News 535(7610):29. https://doi.org/10.1038/535029a

34. Liu L, Li X, Dutta PK, Wang J (2013) Room temperature impedance spectroscopy-based sensing of formaldehyde with porous $\mathrm{TiO}_{2}$ under UV illumination. Sens Actuators B Chem 185:1-9. https://doi.org/10.1016/j.snb.2013.04.090

35. Ma J, Wang S, Chen D, Wang W, Zhang Z, Song S, Yu W (2018) $\mathrm{ZnO}$ piezoelectric film resonator modified with multi-walled carbon nanotubes/polyethyleneimine bilayer for the detection of trace formaldehyde. Appl Phys A 124(1):56. https://doi. org/10.1007/s00339-017-1481-5

36. Marchand C, Bulliot B, Le Calvé S, Mirabel P (2006) Aldehyde measurements in indoor environments in Strasbourg (France). Atmos Environ 40(7):1336-1345. https://doi.org/10.1016/j. atmosenv.2005.10.027

37. Maruo YY, Yamada T, Nakamura J, Izumi K, Uchiyama M (2010) Formaldehyde measurements in residential indoor air using a developed sensor element in the Kanto area of Japan. Indoor Air 20(6):486-493. https://doi.org/10.1111/j.1600-0668.2010.00670 .$x$

38. Mentese S, Güllü G (2006) Variations and sources of formaldehyde levels in residential indoor air in Ankara, Turkey. Indoor Built Environ 15(3):273-281

39. Michałowicz J, Duda W (2007) Phenols-sources and toxicity. Polish J Environ Stud 16(3):347-362

40. Murphy MW, Lando JF, Kieszak SM, Sutter ME, Noonan GP, Brunkard JM, McGeehin MA (2013) Formaldehyde levels in FEMA-supplied travel trailers, park models, and mobile homes in Louisiana and Mississippi. Indoor Air 23(2):134-141. https://doi.org/10.11 11/j.1600-0668.2012.00800.x

41. Musak L, Smerhovsky Z, Halasova E, Osina O, Letkova L, Vodickova L, Polakova V, Buchancova J, Hemminki K, Vodicka P (2013) Chromosomal damage among medical staff occupationally exposed to volatile anesthetics, antineoplastic drugs, and formaldehyde. Scand J Work Environ Health 39:618-630. https:// doi.org/10.5271/sjweh.3358

42. Okoth-Okelloh AM, Ogonda BA, Ogolla S, Tonui WK, Onyango R, Maseno K (2013) Quality assurance for occupational health and safety administration (OSHA) In the morgue: the impact of SOP domestication on implementation and practice of universal safety precautions in Kenya. Qual Assur 3(19), ISSN 2224-3208

43. Ongwandee M, Moonrinta R, Panyametheekul S, Tangbanluekal C, Morrison G (2009) Concentrations and strengths of formaldehyde and acetaldehyde in office buildings in Bangkok, 
Thailand. Indoor Built Environ 18(6):569-575. https://doi. org/10.1177/1420326X09349897

44. Papapostolou V, Zhang H, Feenstra BJ, Polidori A (2017) Development of an environmental chamber for evaluating the performance of low-cost air quality sensors under controlled conditions. Atmos Environ 171:82-90. https://doi.org/10.1016/j.atmos env.2017.10.003

45. Popovicheva O, Timofeev M, Persiantseva N, Jefferson MA, Johnson M, Rogak SN, Baldelli A (2019) Microstructure and chemical composition of particles from small-scale gas flaring. Aerosol Air Qual Res 19(10):2205-2221. https://doi.org/10.4209/ aaqr.2019.04.0177

46. Qaderi F, Sayahzadeh AH, Azizpour F, Vosughi P (2019) Efficiency modeling of serial stabilization ponds in treatment of phenolic wastewater by response surface methodology. Int J Environ Sci Technol 16(8):4193-4202. https://doi.org/10.1007/s1376 2-018-1816-6

47. Qin X, Wang R, Tsow F, Forzani E, Xian X, Tao N (2014) A colorimetric chemical sensing platform for real-time monitoring of indoor formaldehyde. IEEE Sens J 15(3):1545-1551

48. Raja DS, Sultana B (2012) Potential health hazards for students exposed to formaldehyde in the gross anatomy laboratory. $J$ Environ Health 74(6):36-41

49. Riccó M, Signorelli C, Pistelli E, Cattani S (2016) Quantitative olfactory disorders and occupational exposure to phenolic resins. Med Pr 67(2):173-186

50. Rovira J, Roig N, Nadal M, Schuhmacher M, Domingo JL (2016) Human health risks of formaldehyde indoor levels: an issue of concern. J Environ Sci Health Part A 51(4):357-363. https://doi. org/10.1080/10934529.2015.1109411

51. Sato T, Breedon M, Miura N (2013) Reduction in ethanol interference of zirconia-based sensor for selective detection of volatile organic compounds. J Electrochem Soc 160(9):B146-B151. https ://doi.org/10.1149/2.007309jes

52. Spinelle L, Gerboles M, Kok G, Persijn S, Sauerwald T (2017) Review of portable and low-cost sensors for the ambient air monitoring of benzene and other volatile organic compounds. Sensors 17(7):1520. https://doi.org/10.3390/s17071520

53. Statheropoulos M, Agapiou A, Spiliopoulou C, Pallis GC, Sianos E (2007) Environmental aspects of VOCs evolved in the early stages of human decomposition. Sci Total Environ 385(13):221-227. https://doi.org/10.1016/j.scitotenv.2007.07.003

54. Szulczyński B, Gębicki J (2017) Currently commercially available chemical sensors employed for detection of volatile organic compounds in outdoor and indoor air. Environments 4(1):21. https://doi.org/10.3390/environments4010021
55. Trivanovic U, Corbin JC, Baldelli A, Peng W, Yang J, Kirchen P, Miller JW, Lobo P, Gagné S, Rogak SN (2019) Size and morphology of soot produced by a dual-fuel marine engine. J Aerosol Sci 138:105448. https://doi.org/10.1016/j.jaerosci.2019.105448

56. Vélez MP, Arbuckle TE, Fraser WD (2015) Female exposure to phenols and phthalates and time to pregnancy: the MaternalInfant Research on Environmental Chemicals (MIREC) Study. Fertil Steril 103(4):1011-1020. https://doi.org/10.1016/j.fertn stert.2015.01.005

57. Wang J, Zhan D, Wang K, Hang W (2017) The detection of formaldehyde using microelectromechanical acoustic resonator with multiwalled carbon nanotubes-polyethyleneimine composite coating. J Micromech Microeng 28(1):015003. https://doi. org/10.1088/1361-6439/aa9c23

58. Wantke F, Focke $M$, Hemmer W, Bracun R, Wolf-Abdolvahab S, Götz M, Jarisch R, Götz M, Tschabitscher M, Gann M, Tappler P (2000) Exposure to formaldehyde and phenol during an anatomy dissecting course: sensitizing potency of formaldehyde in medical students. Allergy 55(1):84-87. https://doi.org/10.103 4/j.1398-9995.2000.00307.x

59. Weiler MD (2016) Formaldehyde exposure during cadaver transport. Doctoral dissertation, University of Toledo

60. Whitehead MC, Savoia MC (2008) Evaluation of methods to reduce formaldehyde levels of cadavers in the dissection laboratory. Clin Anat 21(1):75-81. https://doi.org/10.1002/ca.20567

61. Wongniramaikul W, Limsakul W, Choodum A (2018) A biodegradable colorimetric film for rapid low-cost field determination of formaldehyde contamination by digital image colorimetry. Food Chem 249:154-161. https://doi.org/10.1016/j.foodc hem.2018.01.021

62. Zhao L, Li X, Wang J, Yao P, Akbar SA (2016) Detection of formaldehyde in mixed VOCs gases using sensor array with neural networks. IEEE Sens J 16(15):6081-6086. https://doi.org/10.1109/ jsen.2016.2574460

63. Zhang D, Liu J, Jiang C, Liu A, Xia B (2017) Quantitative detection of formaldehyde and ammonia gas via metal oxide-modified graphene-based sensor array combining with neural network model. Sens Actuators B Chem 240:55-65. https://doi. org/10.1016/j.snb.2016.08.085

Publisher's Note Springer Nature remains neutral with regard to jurisdictional claims in published maps and institutional affiliations. 